\title{
An exploration of the rapid transformation method for Dunaliella salina system
}

\author{
Guannan Song ${ }^{1 \dagger}$, Wan Wang ${ }^{1 \dagger}$, Lina Hu${ }^{1}$, Yu Liu ${ }^{1}$, Aifang Li ${ }^{1}$, Jingxia Du ${ }^{1,2}$, Jiao Wang ${ }^{1}$, Mengyuan Jia \\ and Shuying Feng ${ }^{1,2^{*}}$
}

\begin{abstract}
As a new expression system, Dunaliella salina (D. salina) has bright prospects and applications in various fields. However, its application is currently restricted because of the low expression and instability of foreign gene in $D$. salina cells. During genetic operation, transformation is a crucial step for genes expression in D. salina system. Although several transformation methods are existing currently, many inherent deficiencies and limitations still can be found in actual practice. Thus, we attempted to set up a rapid transformation method using the change of salt concentrations for $D$. salina. Based on osmotic pressure difference, exogenous genes can be spontaneously transferred into $D$. salina cells. After that, transformed D. salina cells were subjected to histochemical and molecular analysis. The results showed that the reporter gene, beta-glucuronidase genes were successfully expressed in the positive transformants, and detected in all of transformed cells by PCR analysis. Moreover, different transformation parameters, containing the salt gradient, time, dye dosage and Triton X-100 concentration, were optimized to obtain an optimal transformation result. Taken together, we preliminarily established a rapid transformation method with the features of fast, simple, economic, and high-efficient. This method will provide a strong genetic manipulation tool for the future transformation of $D$. salina system.
\end{abstract}

Keywords: Dunaliella salina, Transformation, Salt gradient, High efficiency, Rapid method

\section{Introduction}

Currently, microalga as a versatile expression system that has been widely used in the fields of vaccine (Dehghani et al. 2018), bio-based chemicals (Ng et al. 2017), metabolic engineering (Anila et al. 2016), pharmaceutical engineering (Zhang et al. 2018), and so on. Among them, since Dunaliella salina (D. salina) offers numerous special advantages, it has been exploited as a novel expression system for production of recombinant proteins (Poungpair et al. 2014; Feng et al. 2014a, b, c). Although several exogenous genes have been transformed into $D$. salina, such as the human canstatin (Feng et al. 2014a), soybean kunitz trypsin inhibitor (Chai et al. 2012), and white spot syndrome virus VP28 (Feng et al. 2014b), and interferon-thymosin fusion proteins (Zhang et al. 2018),

\footnotetext{
*Correspondence: fshy001@haust.edu.cn

${ }^{\dagger}$ Guannan Song and Wan Wang contributed equally to this work

${ }^{1}$ Medical College, Henan University of Science and Technology, No. 263

Kaiyuan Avenue, Luoyang 471023, Henan, China

Full list of author information is available at the end of the article
}

most of them exhibited the low and instable expression in nuclear system of $D$. salina. Thus, improving the expression level of foreign gene in $D$. salina cells is an urgent issue for current study.

In the genetic operation of D. salina, transformation is a key step for expression of exogenous genes. So far, several transformation methods have been established for D. salina system, like electroporation (Lü et al. 2009), bombardment particle (Tan et al. 2005), and glass beads (Feng et al. 2009). Each of them has some inherent disadvantages with respect to simplicity, economy, operability and reproducibility, which made them have great limitations in the practical transformation of D. salina. Given this, more efficient and rapid approach should be established for future transformation of $D$. salina.

Due to it can grow in $0.1-5 \mathrm{M}$ salt concentration, D. salina has the remarkable halotolerant ability in practical culture (Feng et al. 2014b). Based on this feature, we attempted to establish a rapid transformation method using the difference of salt gradients. When salt 
gradient decreased from high to low, cells permeability was increased instantaneously and then exogenous plasmids introduced simultaneously into $D$. salina cells. Moreover, to obtain an optimal transformation rate, we optimized the different transformation parameters which including salt gradient, time, dye dosage and Triton X-100 concentration. Under the optical transformation conditions, exogenous genes could be high-efficiently transferred into D. salina cells. Our study showed that a simple and rapid transformation method successfully established for transformation of $D$. salina cells.

\section{Materials and methods}

\section{Algal strain and culture condition}

The D. salina strain UTEX-1644 was purchased from the Culture Collection of Algae (University of Texas, USA). Under light intensity of $50 \mu \mathrm{M}$ photon $\mathrm{m}^{-2} \mathrm{~s}^{-1}$ with a $12 \mathrm{~h}$-light/day, $D$. salina cells were cultured in $2 \mathrm{~L}$ beaker with the modified PKS medium at $26^{\circ} \mathrm{C}$ (Feng et al. 2009). The modified liquid medium consist of $1.5 \mathrm{M} \mathrm{NaCl}, 1 \mu \mathrm{M}$

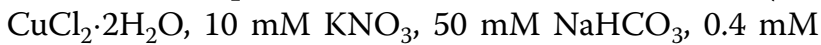
$\mathrm{KH}_{2} \mathrm{PO}_{4}, 185 \mu \mathrm{M} \mathrm{H}_{3} \mathrm{Bo}_{3}, 2 \mu \mathrm{M} \mathrm{FeCl} \cdot 6 \mathrm{H}_{2} \mathrm{O}, 5 \mathrm{mM}$ $\mathrm{MgSO}_{4} \cdot 7 \mathrm{H}_{2} \mathrm{O}, 5 \mu \mathrm{M}$ EDTA, $1 \mu \mathrm{M}\left(\mathrm{NH}_{4}\right) \mathrm{Mo}_{7} \mathrm{O}_{24} \cdot 4 \mathrm{H}_{2} \mathrm{O}$, $7 \mu \mathrm{M} \mathrm{MnCl}_{2} \cdot 4 \mathrm{H}_{2} \mathrm{O}, 1 \mu \mathrm{M} \mathrm{ZnCl}_{2}, 1 \mu \mathrm{M} \mathrm{CoCl}_{2} \cdot 6 \mathrm{H}_{2} \mathrm{O}$, and $0.2 \mathrm{mM} \mathrm{CaCl}_{2}$. When growth reached logarithmic phase (about $10^{5}-10^{6}$ cells $/ \mathrm{mL}$ ), D. salina cells were harvested by centrifugation for future use. After washed three times with the fresh medium, D. salina cells were re-suspended and the cells concentration was adjusted to about $10^{6}$ cells $/ \mathrm{mL}$ for further use.

\section{Manipulation protocols with the salt gradients}

Ethidium bromide (EB) was purchased from Solarbio Science \& Technology Co. Ltd (Beijing, China); and was formulated into different concentration gradients. Triton X-100 was purchased from Baoxin biotechnological Co. Ltd (Luoyang, China), and was made as a $0.1 \%$ stock solution. After $8 \mathrm{~h}$ cultured in $1 \mathrm{M}$ medium, $D$. salina cells were harvested and then re-suspended with the $0.1 \mathrm{M}$ fresh medium. Meanwhile, different concentrations of Triton X-100 $(5,10,15,20,25$ and $30 \mu \mathrm{L})$ and EB $(1.25 \%$, $2.5 \%, 3.75 \%, 5 \%, 6.25 \%$ and $7.5 \%)$ were immediately added to $1 \mathrm{~mL} D$. salina separately. And then, this mixture was blended briefly using inverting tube. D. salina cells were observed quickly at the point in time of $60 \mathrm{~s}$, $90 \mathrm{~s}, 120 \mathrm{~s}, 150 \mathrm{~s}$ and $180 \mathrm{~s}$ under a fluorescence microscope. In this experiment, four factors were determined orderly which including salt gradient, time, TritonX-100 concentration and EB amount. When one variable of four variables was optimized, the other three parameters were unchanged as described above. The independent experiments were repeated three times at least.

\section{Transformation of $D$. salina cells with the plasmids}

The plasmids pCAMBIA1303 were purchased from Guangyu biotechnological Co. Ltd (Shanghai, China), which including a selective gene $\left(\mathrm{Kan}^{+}\right)$and a report gene ( $\beta$-glucuronidase, GUS). The modified plasmids pCAMBIA1303-N, in which GUS gene fragment was deleted, were constructed in our lab that used as the negative control plasmids. The restriction endonuclease sites and other features were indicated in Fig. 1. Under the optimal transformation conditions, D. salina cells were transformed with the plasmids pCAMBIA1303 and pCAMBIA1303-N respectively. In the $1 \mathrm{~mL}$ culture of $D$. salina cells, $5.46 \mu \mathrm{g}$ vector DNA was added and then mixed briefly at $800 \mathrm{~g}$ on a Vortex mixer for $60 \mathrm{~s}$. More than $90 \%$ of surviving transformed $D$. salina cells were cultured in liquid medium at $26{ }^{\circ} \mathrm{C}$ with a $12 \mathrm{~h}$-light/day for $48 \mathrm{~h}$. After that, D. salina cells were collected and then analyzed with the histochemical staining (Feng et al. 2009) and PCR analysis (Chen et al. 2001). The negative control and blank control were treated with the same processes using the negative control plasmids and the blank control (liquid medium), respectively. The repeated experiments were conducted three times at least.

\section{Statistical analysis}

In this study, all the numbers came from independently repeated experiments at least three times. The transformants were counted by the number of blue cells in total transformed cells. Using SPSS version 17.0, all data were carried out with one-way analysis of variance. In which, the value $P<0.05$ was considered statistically significant in all statistical analyses.

\section{Results \\ Morphology of stained $D$. salina cells with EB}

To measure the difference of treated $D$. salina lines, cells with fluorescence were counted under the fluorescence microscopy. After EB staining, morphology and color of each cell line was observed under different light sources (Fig. 2a1, b1). Under the red and green fluorescent sources, wild $D$. salina cells shown the red and green color correspondingly (Fig. 2a2, a3). Meanwhile, stained D. salina cells appeared the lighter color under the same fluorescent source (Fig. 2b2, b3). But the cells nucleus shown a deeper color under the red and green fluorescent sources. Under the merged fluorescence sources (red with green), wild type and stained cells shown the lighter green color and yellow color separately (Fig. 2a4, b4). After statistical analysis, the number of cells with fluorescence could approach up to $100 \%$. 


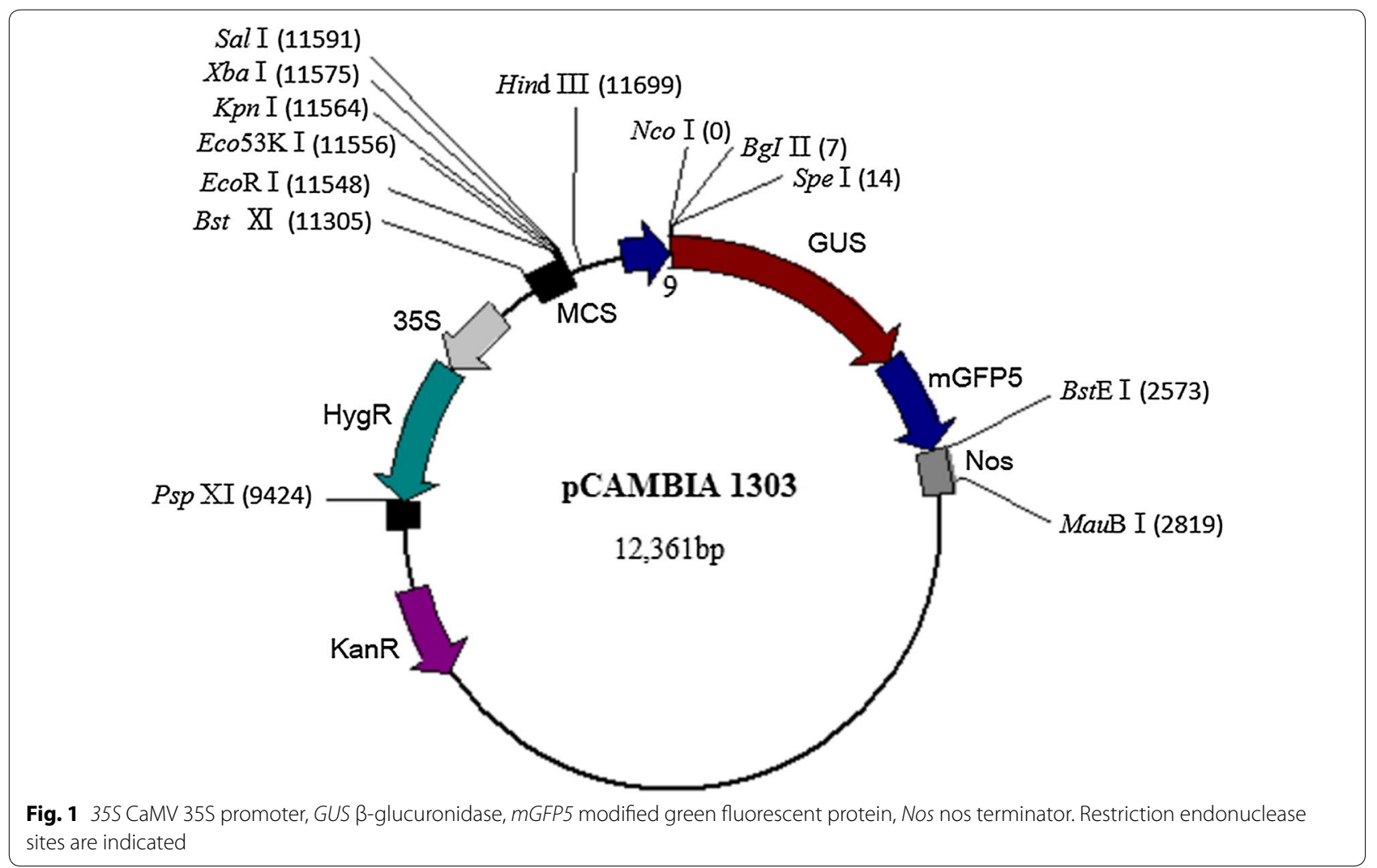

\section{Optimization of different parameters}

To obtain the optimal transformation rate, four parameters have been optimized in turn which containing salt gradient, time, EB and TritonX-100 concentration in this study. Firstly, transformants increased most significantly along with the salt concentration decreasing (Fig. 3a). When salt concentration decreased to $0.1 \mathrm{M}$, $D$. salina cells with fluorescence reached as high as $100 \%(P<0.01)$. However, if salt concentration was less than $0.1 \mathrm{M}$, the number of transformants decreased distinctly. Secondly, transformation time has a great influence on the transformation results. Between 60 and $150 \mathrm{~s}$, the number of transformants increased noticeably with the extension of time, and the optimal time was from 90 to $120 \mathrm{~s}$ (Fig. $3 \mathrm{~b}, P<0.05$ ). Followed further extension of time, positive transformants did not increase correspondingly due to cells rupture. Thirdly, the number of transformants was closely associated with the Triton X-100 concentration. As shown in Fig. 3c, transformants were increased with the Triton X-100 concentration in a dose-dependent manner. Within range of 5-15 $\mu \mathrm{L}$, the number of transformants increased from 85 to $98.6 \%$. When TritonX-100 concentration was higher than $15 \mu \mathrm{L}$, a significant reduction of transformants was observed due to the strong dissolution of Triton X-100 (Fig. 3c, $P<0.05$ ). Finally, the maximum number of transformants was obtained with $3.75 \% \mathrm{~EB}$ concentration under mentioned above conditions (Fig. $3 \mathrm{~d}, P<0.05$ ). But as the EB concentration increased, the number of transformations did not improve correspondingly. After completely analyzed the transformation results, the ideal transformation rate could be achieved under the following conditions: $10 \% \mathrm{~EB}$ and $15 \mu \mathrm{L} 0.1 \%$ Triton X-100 were added to $1 \mathrm{~mL}$ culture with the treatment of $90-120 \mathrm{~s}$ in $0.1 \mathrm{M}$ salt concentration.

\section{Detection of GUS gene expression}

After histochemical staining, positive transformants showed the blue color partially (Fig. 4b), while negative control group was not shown (Fig. 4a). This transformation result was further confirmed by PCR analysis. As shown in Fig. 5, GUS-specific products of $1807 \mathrm{bp}$ were detected in the all of transformed lines, but not in the negative control. The size of amplified fragments was consistent with the positive control. These results indicates that exogenous genes have been introduced into $D$. salina cells and further successfully expressed in the cells. The genetic stability analysis of transformed $D$. salina strains will be studied in next works. 


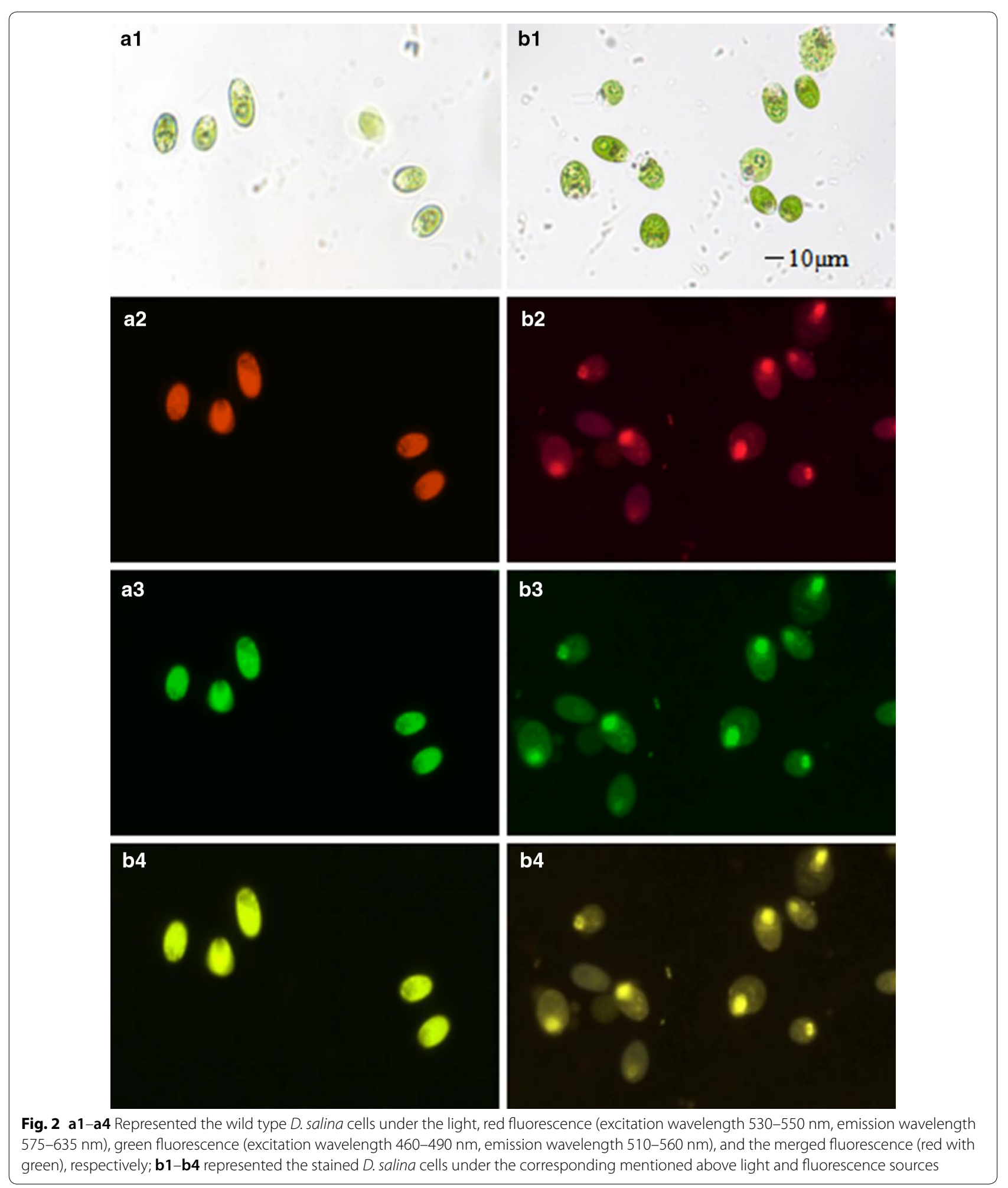



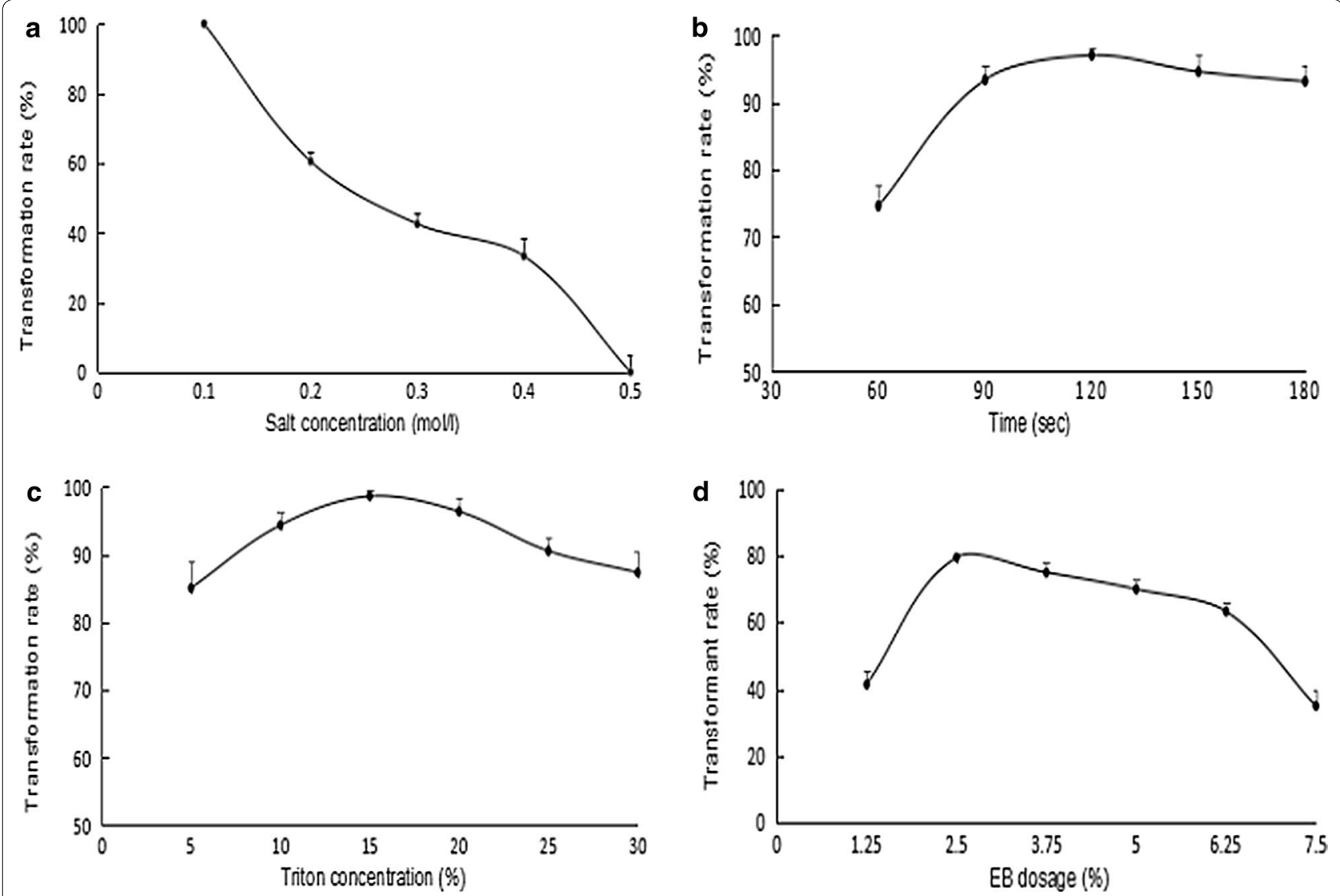

Fig. 3 a-d Denoted the effects of salt gradient, time, concentration of Triton X-100 and EB on the number of transformants, respectively. a The number of transformants increased significantly along with the decrease of salt concentration. When the salt concentration was less than $0.1 \mathrm{M}$, the number of transformants decreased significantly with the highest value. $\mathbf{b}$ The number of transformants increased noticeably with the extension of transformation time. Following the further extension of time, the number of transformants did not increase correspondingly. c The increasing of transformants was associated with the Triton X-100 concentration in a dose-dependent manner. When concentration of Triton X-100 was over than $3.75 \%$, the number of transformants was significantly decreased because of the strong dissolution. $\mathbf{d}$ The maximum number of transformants can be achieved with the $10 \%$ EB concentration, and decreased significantly at the other concentrations
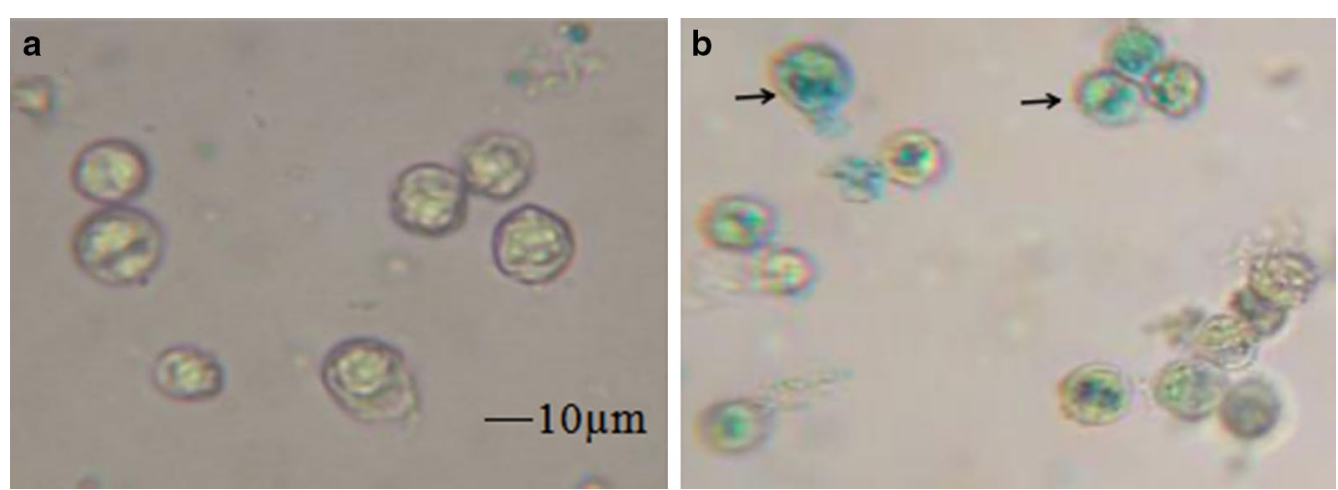

Fig. 4 a Negative control: D. salina cells were transformed with the plasmids PCAMBIA1303-N; b transformed group: D. salina cells were transformed with the plasmids pCAMBIA1303. Arrow represented the positive transformants with the blue color 


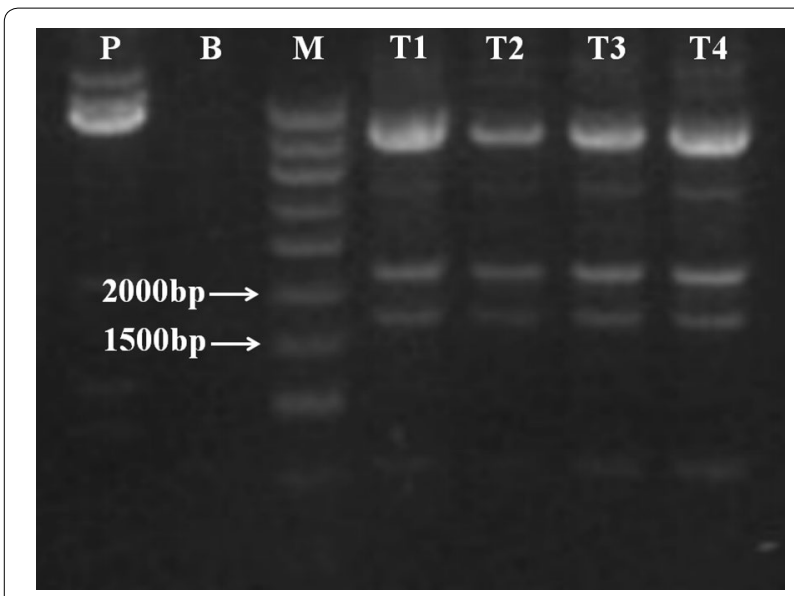

Fig. 5 P plasmid pCAMBIA1303, B blank control, M DNA ladder marker, T1-T4 different transformed $D$. salina cells lines

\section{Discussion}

To improve the gene expression in D. salina cells, and then facilitate the maturation of $D$. salina system, a robust transformation tool is essential for production of recombinant proteins. Since the shortcomings of current methods, we attempted to explore a simple and rapid transformation method using salt gradient for D. salina. Using EB as the staining dye, different transformation parameters were fast determined in the study. Among them, effect of salt concentration is the most obvious factor on the transformation rate. The transformation rate increased significantly along with the decrease of salt concentration. When salt concentration was less than $0.1 \mathrm{M}$, the transformation rate greatly reduced due to the water absorption of cells that ended up with the cells rupture. Although followed the increasing of time extension, the transformation rate declined distinctly owing to cells lysis when time was more than $120 \mathrm{~s}$. Because Triton X-100 can dissolve the lipid bilayer of cells membrane, the tremendous destruction of Triton X-100 leads to a remarkable decrease of the number of transformants when its concentration was over than $15 \mu \mathrm{L}$. Collectively, in present study, the optimal transformation conditions was determined as follows: adding $15 \mu \mathrm{L} 0.1 \%$ Triton $\mathrm{X}-100$ and $10 \% \mathrm{~EB}$ to $1 \mathrm{~mL}$ culture $(0.1 \mathrm{M}$ salt concentration) with the treating time of 90-120 s.

In this study, relied on the features of quick, high sensitive, efficient staining, EB was used to rapidly identify the transformation results. Although the transformation of EB is different from that of plasmids, its transformation processes and parameters can be referred to the next transformation work of $D$. salina system. Here, we preliminarily stated the feasibility of this method for transformation of $D$. salina cells. Compared with the other methods, it has a significant transformation efficiency and the minimal damage to cells (Lü et al. 2009; Tan et al. 2005; Feng et al. 2009; Chai et al. 2012). However, the other transformation parameters were not optimized for transformation of plasmids into $D$. salina cells, which would be deeply studied in next works. The positive transformants were only identified at the level of cells and nucleic acid. The bio-activities of recombinant proteins were still not analyzed, which was the work in progress. Taken together, all the results demonstrated that an alternative rapid method has been successfully established for D. salina transformation. And it will provide a strong genetic manipulation tool for the future transformation of $D$. salina system.

\section{Abbreviations}

D. salina: Dunaliella salina; EB: ethidium bromide; GUS: $\beta$-glucuronidase.

\section{Acknowledgements}

The authors gratefully acknowledge Prof. Russell Carlson of Department of Biochemistry \& Molecular Biology of University of Georgia for modifying and polishing this manuscript.

\section{Authors' contributions}

GN, WW, LN carried out the experiments of EB staining and drafted the manuscript. YL, AF, JX optimized the transformation parameters of this study. JW, MY, SY made contribution to the transformation of foreign genes into D. salina cells. SY supervised the project and revised the manuscript. All authors read and approved the final manuscript.

\section{Funding}

This work was funded by the National Natural Science Foundation of China (Nos. 31571289, U1804112), the Young Backbone Teacher Project of Henan Province Universities, China (No. 2012GGJS-080).

\section{Availability of data and materials}

The data of this article is included within the article. And also, the data and materials can also be requested from the corresponding author and the first author.

Ethics approval and consent to participate Not applicable.

\section{Consent for publication}

Not applicable.

\section{Competing interests}

The authors declare that they have no competing interests.

\section{Author details}

${ }^{1}$ Medical College, Henan University of Science and Technology, No. 263 Kaiyuan Avenue, Luoyang 471023, Henan, China. ${ }^{2}$ Medical Research Center, Henan University of Science and Technology, Luoyang 471023, Henan, China.

Received: 24 August 2019 Accepted: 25 October 2019

Published online: 09 November 2019

\section{References}

Anila N, Simon DP, Chandrashekar A, Ravishankar GA, Sarada R (2016) Metabolic engineering of Dunaliella salina for production of ketocarotenoids. Photosynth Res 127(3):321-333 
Chai XJ, Chen HX, Xu WQ, Xu YW (2012) Expression of soybean kunitz trypsin inhibitor gene SKTI in Dunaliella salina. J Appl Phycol 25:139-144

Chen Y, Wang YQ, Sun YR, Zhang LM, Li WB (2001) Highly efficient expression of rabbit neutrophil peptide-1 gene in Chlorella ellipsoidea cells. Curr Genet 39(5-6):365-370

Dehghani J, Adibkia K, Movafeghi A, Barzegari A, Pourseif MM, Maleki Kakelar H, Golchin A, Omidi Y (2018) Stable transformation of Spirulina (Arthrospira) platensis: a promising microalga forproductionofedible vaccines. Appl Microbiol Biotechnol 102(21):9267-9278

Feng SY, Xue LX, Liu HT, Lu PJ (2009) Improvement of efficiency of genetic transformation for Dunaliella salina by glass beads method. Mol Biol Rep 36(6):1433-1439

Feng SY, Feng WP, Zhao L, Gu HH, Li QH, Shi K, Guo SX, Zhang NN (2014a) Preparation of transgenic Dunaliella salina for immunization against white spot syndrome virus in crayfish. Arch Virol 159(3):519-525

Feng SY, Li XB, Xu ZS, Qi JJ (2014b) Dunaliella salina as a novel host for the production of recombinant proteins. Appl Microbiol Biotechnol 98(10):4293-4300

Feng S, Li S, Li Q, Shi K, Xue L (2014c) Preparation of recombinant human canstatin using transgenic Dunaliella salina. Acta Biochim Biophys Sin (Shanghai) 46(5):428-430
Lü PJ, Yan HX, Li J, Liu HT, Lu XJ, Xue LX (2009) An optimal electroporation system for Dunaliella salina. Sheng Wu Gong Cheng Xue Bao 25(4):520-525

Ng IS, Tan SI, Kao PH, Chang YK, Chang JS (2017) Recent developments on genetic engineering of microalgae for biofuels and bio-based chemicals. Biotechnol J 12:1600644

Poungpair O, Bangphoomi K, Chaowalit P, Sawasdee N, Saokaew N, Choowongkomon K, Chaicumpa W, Yenchitsomanus PT (2014) Generation of human single-chain variable fragment antibodies specific to dengue virus non-structural protein 1 that interfere with the virus infectious cycle. MAbs 6(2):474-482

Tan CP, Qin S, Zhang Q, Jiang P, Zhao FQ (2005) Establishment of a micro-particle bombardment transformation system for Dunaliella salina. J Microbiol 43(4):361-365

Zhang ZH, He P, Zhou Y, Xie XH, Feng SY, Sun CY (2018) Anti-HBV effect of interferon-thymosin a1 recombinant proteins in transgenic Dunaliella salina in vitro and in vivo. Exp Ther Med 16(2):517-522

\section{Publisher's Note}

Springer Nature remains neutral with regard to jurisdictional claims in published maps and institutional affiliations.

\section{Submit your manuscript to a SpringerOpen ${ }^{\circ}$ journal and benefit from:}

- Convenient online submission

- Rigorous peer review

- Open access: articles freely available online

- High visibility within the field

- Retaining the copyright to your article

Submit your next manuscript at $\gg$ springeropen.com 